\title{
Article \\ Effects of Different Amounts of Nb Doping on Electrical, Optical and Structural Properties in Sputtered $\mathrm{TiO}_{2-x}$ Films
}

\author{
Daniel Dorow-Gerspach ${ }^{1, *}$, Dieter Mergel $^{2}$ and Matthias Wuttig ${ }^{1}$ \\ 1 Institute of Physics (IA), RWTH Aachen University, 52074 Aachen, Germany; \\ m.wuttig@physik.rwth-aachen.de \\ 2 Thin Film Technology Group, Faculty of Physics, University of Duisburg-Essen, 47057 Duisburg, Germany; \\ Dieter.Mergel@Uni-DuE.De \\ * Correspondence: dorow-gerspach@phyik.rwth-aachen.de
}

check for updates

Citation: Dorow-Gerspach, D.; Mergel, D.; Wuttig, M. Effects of Different Amounts of $\mathrm{Nb}$ Doping on Electrical, Optical and Structural Properties in Sputtered $\mathrm{TiO}_{2-\mathrm{x}}$ Films. Crystals 2021, 11, 301. https:// doi.org/10.3390/cryst11030301

Academic Editor: Shujun Zhang

Received: 9 February 2021

Accepted: 12 March 2021

Published: 17 March 2021

Publisher's Note: MDPI stays neutral with regard to jurisdictional claims in published maps and institutional affiliations.

Copyright: (c) 2021 by the authors. Licensee MDPI, Basel, Switzerland. This article is an open access article distributed under the terms and conditions of the Creative Commons Attribution (CC BY) license (https:// creativecommons.org/licenses/by/ $4.0 /)$.

\begin{abstract}
Highly conductive $\mathrm{TiO}_{2}$ films with different $\mathrm{Nb}$ doping levels (up to 5 at $\%$ ) were prepared by reactive DC magnetron sputtering under precise control of the oxygen partial pressure. They were deposited on unheated substrates, covered with a protective $\mathrm{Si}_{3} \mathrm{~N}_{4}$ layer, and subsequently annealed at $300{ }^{\circ} \mathrm{C}$. The doping efficiency of $\mathrm{Nb}$ is greater than $90 \%$. Conductivity is a maximum for a partly oxidized target in the transition range. The best films exhibit a resistivity of $630 \mu \Omega \mathrm{cm}$ and a mobility of $7.6 \mathrm{~cm}^{2} / \mathrm{Vs}$ combined with a high transparency above $70 \%$. Comparing the behavior of undoped and $\mathrm{Nb}$-containing films, intrinsic limits of the conductivity in the $\mathrm{TiO}_{2-\mathrm{x}}: \mathrm{Nb}$ system could be observed, and a consistent model explaining these findings is presented. The conductivity is limited—by decreasing electron density due to $\mathrm{Nb}$ oxidation-by increasing incorporation formation of $\mathrm{Nb}_{2} \mathrm{O}_{5}$ clusters as scattering centers with increasing oxygen partial pressure and $\mathrm{Nb}$ concentration, by a transition from the crystalline to the amorphous state of the films below a critical oxygen partial pressure.
\end{abstract}

Keywords: $\mathrm{Nb}$ doping; titanium dioxide; electrical properties; anatase; reactive sputtering; transparent conducting oxide

\section{Introduction}

Modern displays, solar cells, and other applications need layers as front electrodes that are both conductive and transparent [1-3]. The materials of choice are currently oxides of metals such as Ga, In, Cd, Sn, and Zn, so-called transparent conducting oxides (TCOs) [4]. They all have in common the fact that their conduction band is built from empty s-orbitals, enabling high electron mobilities.

In $2005, \mathrm{TiO}_{2-\mathrm{x}}$ films doped with $\mathrm{Nb}$ were reported also to fulfill the requirements of high transparency and conductivity [5]. In these materials, electronic transport arises from highly-oriented $d$-orbitals [6], which are less likely to overlap, so that high electron mobilities are not expected. In a previous study, we discussed this issue and the criteria necessary to realize metallic conductivity [7]. There, it was demonstrated how both metallike conductivity and high transparency can be achieved in undoped $\mathrm{TiO}_{2-x}$ and why the conductivity values and temperature behavior reported in the literature vary so much.

For all TCOs, including $\mathrm{TiO}_{2-x}$, charge carriers in addition to the intrinsic ones are necessary to obtain conductivities large enough for applications. This is achieved by doping the matrix oxide with another metal of higher valence. It must have a similar electron configuration as the host to achieve a high doping efficiency. $\mathrm{Nb}$ fulfills these criteria for doping of $\mathrm{TiO}_{2}$, as confirmed by density functional theory (DFT) calculations [8,9]. These computations find that $\mathrm{Nb}$ leaves the electronic structure of $\mathrm{TiO}_{2}$ essentially unaltered, so that band transport in $\mathrm{Nb}$-doped $\mathrm{TiO}_{2}$ is possible. Hence, it is not surprising that many studies focus on this dopant for $\mathrm{TiO}_{2}$ [5,10-12]. However, in most studies, only one doping level is investigated and highly elaborated production methods are utilized, which are not 
suitable for large-scale production. Finally, none of them contain a direct comparison with well conductive but undoped films.

Thus, to clarify the influence of $\mathrm{Nb}$ doping on the relevant properties, we have investigated different $\mathrm{Nb}$ concentrations and compared the results with those for undoped, sub-stoichiometric $\mathrm{TiO}_{2-x}$ films. This provides the opportunity to disentangle several effects, including the contribution of oxygen vacancies to the total charge carrier density, or the mobility change with oxygen partial pressure and $\mathrm{Nb}$ concentration.

The practical use of a TCO includes the production as thin layers on a large glass surface. Reactive DC magnetron sputtering is capable of doing that and, in addition, provides a larger growth rate than radio-frequency (RF) sputtering of ceramic targets [13]. Moreover, the understanding of the correlation between $\mathrm{Nb}$ content and film properties is vital for optimization and industrial applicability.

The first important property, the crystal structure of a film, has been investigated by X-ray diffraction (XRD). The electrons in the rutile phase of $\mathrm{TiO}_{2}$ exhibit a very large effective mass inducing hopping transport, as pointed out, among others, by Tang et al. [14]. Therefore, the phase pureness of anatase is mandatory. Thus, the absence of metallic phases like $\mathrm{Nb}, \mathrm{Ti}$, $\mathrm{TiO}$, or other oxides like $\mathrm{Nb}_{2} \mathrm{O}_{5}$ has to be ensured, and thereby also that $\mathrm{Nb}$ is substituting Ti within the crystal.

The main part of this paper investigates the mechanism of charge carrier conduction. We measured the temperature-dependent resistivity $(\rho)$ and Hall effect to derive the density $(n)$ and mobility $(\mu)$ of the charge carriers with the intention to determine the doping efficiency of $\mathrm{Nb}$ and the mobility limits by comparison with the undoped films. Furthermore, we try to disentangle different phenomena that are not observable when only measuring the resistivity. Finally, ultraviolet and visible light (UV/VIS) spectroscopy has been used to measure the transparency of the films.

\section{Materials and Methods}

More details of the preparation are reported in [7]. Borosilicate glass plates (of $20 \mathrm{~mm} \times 20 \mathrm{~mm} \times 0.5 \mathrm{~mm}$ ) were used as substrates. Optical and electrical measurements were performed on an inner area of $1 \mathrm{~cm}^{2}$ size surrounded by a groove on which the layer thickness could be measured with a stylus profiler (Dektak XT from Bruker). It has a reproducibility of $0.4 \mathrm{~nm}$, and we used a stylus with a size of $2 \mu \mathrm{m}$, force $2 \mathrm{mg}$, and scan speed usually about $60 \mu \mathrm{m} / \mathrm{s}$. The accuracy was confirmed by X-ray reflection cross-check measurements (using a PANalytical X'pert Pro system from Philips with $\mathrm{CuK}_{\alpha}$ radiation $(\lambda=1.5405 \AA)$ and $\omega / 2 \theta$ scan from $0^{\circ}$ to $\left.150^{\circ}\right)$.

The custom build vacuum chamber was evacuated to a base pressure below $2 \times 10^{-6}$ mbar, and a target-substrate distance of $55 \mathrm{~mm}$ was chosen. Computer-controlled mass flow controllers inserted argon (purity 4.8, i.e., 99.998 vol\%), oxygen (purity 5.5), and nitrogen (purity 5.0), ensuring a constant pressure of 1 Pa during sputtering, monitored by a baratron. Metal targets (pure Ti and doped with 1, 2.5, and $5 \mathrm{at} \% \mathrm{Nb}$ ) with a purity of at least $99.99 \%$ were used for reactive DC sputtering at a power of $300 \mathrm{~W}$. Therefore, we assumed that the film had the same composition as the target. For a selection of samples, we checked the $\mathrm{Nb}$ concentration by energy-dispersive X-ray spectroscopy EDX, which showed no deviation within the measurement accuracy.

Stoichiometric $\mathrm{TiO}_{2}$ and $\mathrm{Nb}_{2} \mathrm{O}_{5}$ do not possess any free electrons and thus are insulators. In order to inject electrons in the conduction band, a slight substoichiometry has to be ensured by precise control of the oxygen partial pressure during sputtering. Therefore, the $\mathrm{O}_{2 \mathrm{PP}}$ has to be continuously measured, which was done by a lambda probe from Zirox.

One hour of pre-sputtering within the oxidic regime [15] was used to ensure coverage of all surfaces and a steady-state temperature in the whole chamber. No additional heating of the samples was used; thus, the surface temperature was below $60^{\circ} \mathrm{C}$. Starting from the pure metallic/oxygen-free state, we increased the $\mathrm{O}_{2}$ flux systematically and later decreased it again to record the hysteresis curve $\mathrm{O}_{2 \mathrm{PP}}$ vs. $\mathrm{O}_{2}$ flux. A relative $\mathrm{O}_{2 \mathrm{PP}}$ was employed, defining the $100 \%$ point near the last point in the oxidic regime and $0 \%$ after the process 
dropped to the metallic one. This approach is very helpful because the absolute $\mathrm{O}_{2 \mathrm{PP}}$ values change with target age, sputter power, chamber details, and, what is particularly important in this study, with $\mathrm{Nb}$ concentration. More details of how this working point is defined and on the whole sputtering process can be found elsewhere $[7,16]$. It is only by employing such a relative oxygen scale that films with reproducible properties can be achieved, enabling a comparison of different sputter runs and doping concentrations. Even films produced with other sputter parameters, e.g., sputter power or in other vacuum vessels, can be compared.

Highly conductive and transparent films are only obtained when they are deposited within the unstable regime with a partly oxidized target. To keep this process stable, an active process control (APC) is necessary. We used a feedback loop for the sputter power on a $10 \mathrm{~ms}$ time scale, working on the difference between the set $\mathrm{O}_{2 \mathrm{PP}}$ and its actually measured value. Sputtering was performed at a time-averaged sputter power of roughly $310 \mathrm{~W}$, the same for all films, after the process had been stabilized on a dummy substrate.

Using this APC, the working point in the unstable regime could be stabilized at an $\mathrm{O}_{2 \text { PP }}$ between 15 and $30 \mathrm{mPa}$ with a constancy of better than $\pm 0.1 \mathrm{mPa}$. The deposition rate was found to be inversely proportional to the $\mathrm{O}_{2 \mathrm{PP}}$ applied. In the most relevant sputtering regime, i.e., for a power of $300 \mathrm{~W}$ and at $70 \% \mathrm{O}_{2 \mathrm{PP}}$, the rates were around $30 \mathrm{~nm} / \mathrm{min}$. The deposition times were adapted to create films with thicknesses of about $250 \mathrm{~nm}$. The sample sequence was randomized to avoid potential hidden hysteresis effects from the set parameter $\mathrm{O}_{2 \mathrm{PP}}$.

The $\mathrm{TiO}_{2-x}$ films were covered with a $34 \mathrm{~nm}$ thick $\mathrm{Si}_{3} \mathrm{~N}_{4}$ capping layer to protect the underlying material. Such protection guarantees that the oxide films' oxygen content remains unchanged under post-heating up to temperatures of $1000{ }^{\circ} \mathrm{C}$ [17]. $\mathrm{Si}_{3} \mathrm{~N}_{4}$ was chosen because it can be deposited as an amorphous film and should not significantly alter the crystallization behavior of $\mathrm{TiO}_{2-\mathrm{x}}$. The layers were reactively sputtered using a pulsed DC generator $\left(210 \mathrm{~mA}, 1.2 \mathrm{~Pa}, \mathrm{~N}_{2} / \mathrm{Ar}\right.$ ratio of $\left.1 / 3\right)$ without breaking the vacuum.

The oxide films were amorphous as-deposited (a selection is shown in Figure A1) and fully crystallized to anatase (shown in Figure A2 and [7]) after annealing at a relatively low temperature of $300^{\circ} \mathrm{C}$ for $2 \mathrm{~h}$. This is important, because when the as-deposited films are not entirely amorphous, other studies found that post-heating can result in crystalline mixtures of anatase and rutile, which reduces the conductivity [18].

As several tests showed no pronounced texture of the films, the structure investigations were performed by XRD at grazing incidence (GI) with a PANalytical X'pert Pro system from Philips with $\mathrm{CuK}_{\alpha}$ radiation $(\lambda=1.5405 \AA)$. The detector angle $\theta$ was varied between $20^{\circ}$ and $80^{\circ}$ while keeping the incident angle constant at $\omega=0.7^{\circ}$ to maximize the interaction volume (stepsize $0.04^{\circ}$ and $5 \mathrm{~s}$ per step).

Transmission and direct reflection spectra were measured in the wavelength range of $190 \mathrm{~nm}$ to $1100 \mathrm{~nm}$ with a Lambda 25 UV/VIS system from Perkin Elmer Instruments. In order to get a transparency value that is independent of the interference fringes, we used the envelope method developed by Swanepoel [19] and convoluted the results with the luminosity function (also called a v-lambda curve, $19312^{\circ}$ CIE Standard).

The oxide films were provided with electrical contacts in a four-point Van der Pauw geometry using an HB06 wire bonder from TPT. The wedge of this device could penetrate through the $\mathrm{Si}_{3} \mathrm{~N}_{4}$ capping so that $\mathrm{Al}$ wires with a diameter of $33 \mu \mathrm{m}$ could be soldered to the underlying $\mathrm{TiO}_{2-x}$ film on each of the four edges. Each contact showed ohmic current-voltage characteristics. Van der Pauw geometry was chosen because the electrical measurements do not depend on the contact resistances and the exact sample shape. The electrical measurements were performed in two systems from Quantum Design (Physical Property Measurement System and DynaCool), generating magnetic fields up to $9 \mathrm{~T}$ and enabling stable temperatures between 1.9 and $400 \mathrm{~K}$. It was found that for the films studied here, sweeping between $\pm 3 \mathrm{~T}$ was sufficient (error well below $1 \%$ ). A linear fit of the measured diagonal resistance as the magnetic field changed then yielded the Hall coefficient and thus the electron density. 
Previously, the necessity of a capping layer was illustrated when investigating the $\mathrm{TiO}_{2-x}$ system by showing temperature vs. resistivity data during the annealing of several thin films. Despite Ar flooding, without capping, oxidation was observed, and for higher $\mathrm{O}_{2 \text { PP }}$ levels during deposition, the films became more resistive, even to the point that they could not be measured at all [7]. The investigation of the thickness dependence provides another useful test to confirm the stability of the deposition process and the oxidation resistance of the $\mathrm{Si}_{3} \mathrm{~N}_{4}$ layer. Between $100 \mathrm{~nm}$ and $1 \mu \mathrm{m}$, no systematic resistivity change was observed (e.g., scattering between 200 and $240 \mu \Omega \mathrm{cm}$ at $2 \mathrm{~K}$ for films doped with 5 at $\% \mathrm{Nb}$-doped and an $\mathrm{O}_{2 \mathrm{PP}}$ of $56 \%$ ). For even thinner films, the resistivity often starts to increase slightly. To rule out any geometrical influence, we used films of the same thickness of about $250 \mathrm{~nm}$ in this investigation.

\section{Results and Discussion}

A slightly oxygen-poor atmosphere during film growth is necessary to preserve some amount of oxygen vacancies and donor-active dopants in the deposited films. This is true for standard TCOs $[3,13,20]$ as well as for undoped $\mathrm{TiO}_{2}$ [7] and is shown here for $\mathrm{Nb}$-doped $\mathrm{TiO}_{2}$, too. In Figure 1, the resulting resistivities with respect to the $\mathrm{O}_{2 \mathrm{PP}}$ are depicted, and in Table 1 the properties of the most conductive samples for each doping level are summarized. The 1 at $\%$ level was omitted as they were not as optimized as the others. The resistivities are remarkably low $(630 \mu \Omega \mathrm{cm}$ for the 5 at $\% \mathrm{Nb})$, considering the simple glass substrate and the low deposition/annealing temperature. For example, Sato et al. reported a value of $1300 \mu \Omega \mathrm{cm}$ for DC-sputtered samples with 6.4 at $\% \mathrm{Nb}$ and annealing at $400{ }^{\circ} \mathrm{C}$ in a vacuum [10], and Oka et al. reported $730 \mu \Omega \mathrm{cm}$ with 7 at $\%$ $\mathrm{Nb}$ and annealing at $600{ }^{\circ} \mathrm{C}$ in a vacuum [21]. Mukherjee et al. used RF sputtering and reported a value of $700 \mu \Omega \mathrm{cm}$ with 10 at $\% \mathrm{Nb}$ after annealing at $400{ }^{\circ} \mathrm{C}$ in vacuum [22]. In these studies, an active process control based on cathode voltage and plasma emission of the Ti was utilized.

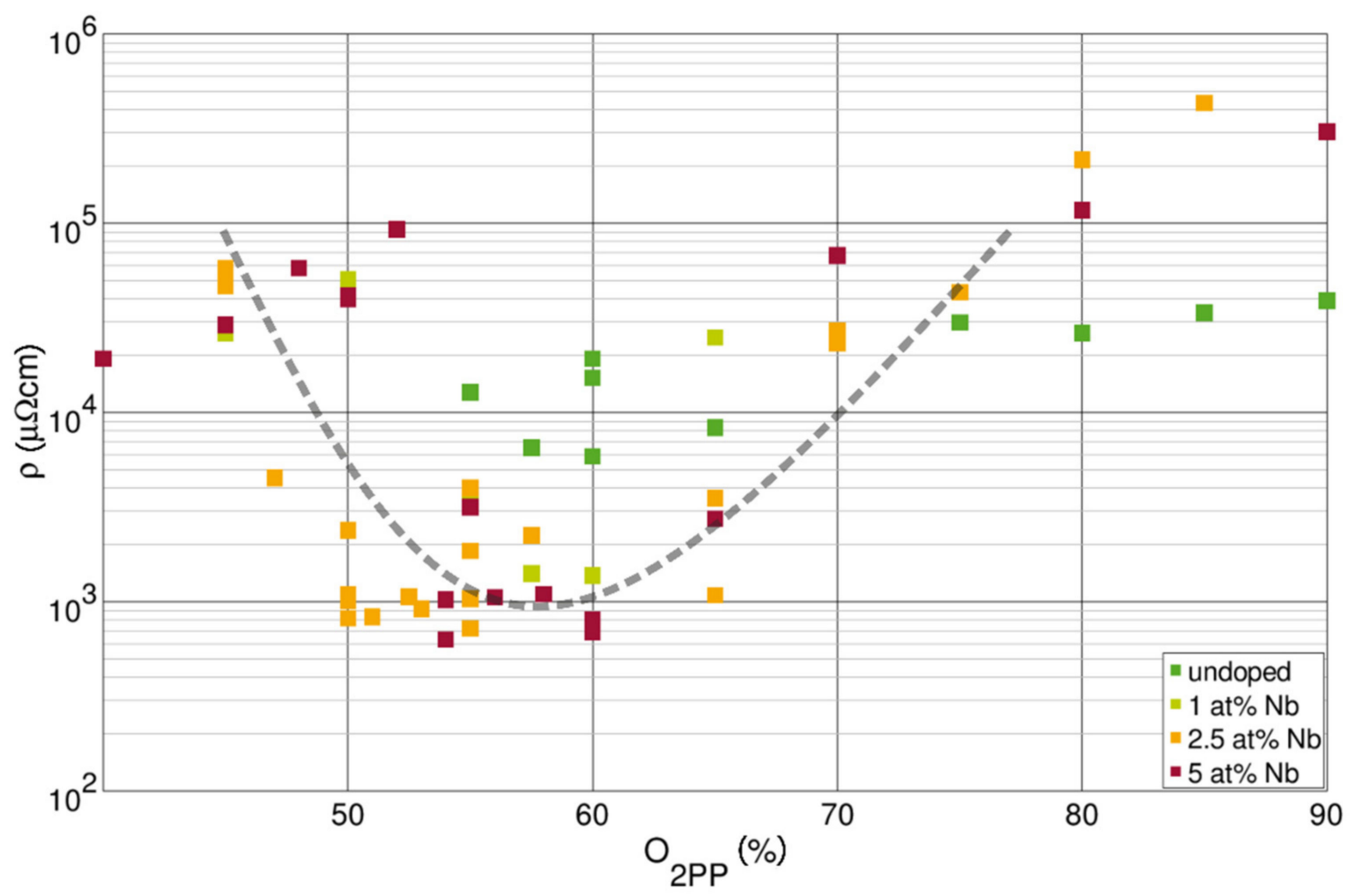

Figure 1. Room temperature resistivity of undoped and $\mathrm{Nb}$-doped $\mathrm{TiO}_{2-x}$ films after annealing as a function of the relative $\mathrm{O}_{2 \mathrm{PP}}$ during the sputter process. A line is given as a guide to the eye to illustrate the overall trend. A minimum of $620 \mu \Omega \mathrm{cm}$ could be reached at $55 \% \mathrm{O}_{2 \mathrm{PP}}$ with $5 \mathrm{at} \% \mathrm{Nb}$. 
Table 1. Resistivity, carrier density and mobility (at room temperature) of the least resistive $\mathrm{TiO}_{2-x}: \mathrm{Nb}$ films sputtered on unheated glass with a SiN capping layer and annealed at $300{ }^{\circ} \mathrm{C}$.

\begin{tabular}{|c|c|c|c|}
\hline $\mathrm{Nb}$ at $\%$ & $\rho(\mu \Omega \mathrm{cm})$ & $n\left(10^{19} / \mathrm{cm}^{3}\right)$ & $\mu\left(\mathrm{cm}^{2} / \mathrm{Vs}\right)$ \\
\hline 0 & 5850 & 6.5 & 16.3 \\
\hline 2.5 & 720 & 80 & 10.8 \\
\hline 5 & 630 & 130 & 7.5 \\
\hline
\end{tabular}

The good resistivities in our investigation could be improved even further, e.g., for the 5 at $\% \mathrm{Nb}$ films to 600 and $550 \mu \Omega \mathrm{cm}$ by post-deposition annealing at 400 and $500{ }^{\circ} \mathrm{C}$ in $\mathrm{Ar}$ atmosphere, respectively. All these films exhibit metal-like conductivity and high transparency, as will be shown later. Films with lower resistivities are possible using a much lower amount of oxygen during sputtering, but they exhibit nearly no transparency anymore.

Although these samples were not produced altogether in one run, not even in the same year, they fit together, when using the relative point in the hysteresis as an ordering scheme. We also tried lower sputtering powers of 100 and $200 \mathrm{~W}$, obtaining similar results.

To understand the origin of this uncommon minimum at $\mathrm{O}_{2 \mathrm{PP}}$ around $55 \%$, we have to disentangle the contribution of several effects. Generally, conductivity can be described by:

$$
\sigma=1 / \rho=e^{*}\left(n_{e}^{*} \mu_{e}+n_{h}^{*} \mu_{h}\right),
$$

where $e$ is the elementary charge, $n_{\mathrm{e}, \mathrm{h}}$ is the concentration of mobile electrons and holes, and $\mu_{\mathrm{e}, \mathrm{h}}$ is their corresponding mobility. As most TCOs and also $\mathrm{TiO}_{2-\mathrm{x}}: \mathrm{Nb}$ are n-type semiconductors; their conductivity is governed by electrons. Thus, the contribution of holes to the overall conductivity can be omitted.

The dependency of the free electron concentration (Figure 2) and their mobility on $\mathrm{O}_{2 \mathrm{PP}}$ was investigated. As expected, $\mathrm{n}$ is reduced by higher amounts of oxygen (fewer oxygen vacancies), whereas it is increased by additional $\mathrm{Nb}$ doping. Therefore, the resistivity minimum is achieved with the highest $\mathrm{Nb}$ concentration of $5 \mathrm{at} \%(\mathrm{Nb} / \mathrm{Ti}$ ratio) used during this work, indicating that $\mathrm{Nb}$ is indeed an effective donor for $\mathrm{TiO}_{2-\mathrm{x}}$.

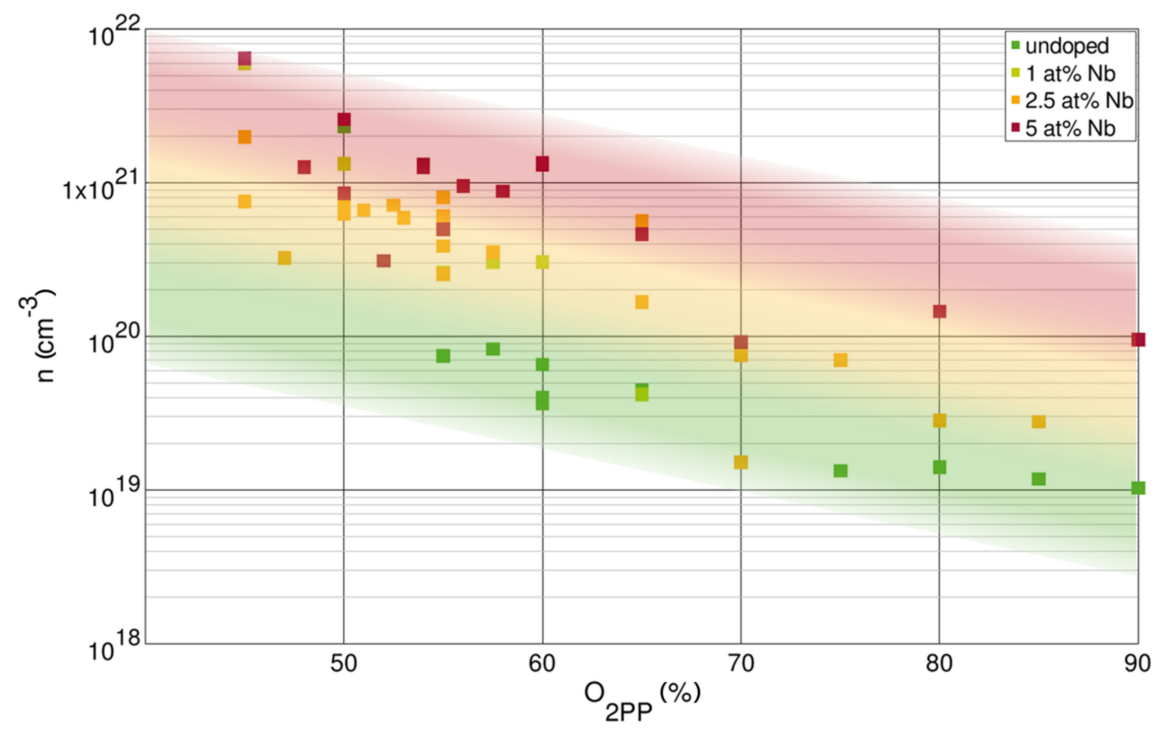

Figure 2. The carrier density $\mathrm{n}$ at room temperature for the resistivities shown in Figure 1 with colored areas as guidance to the eye. Reduction of $n$ with increasing $\mathrm{O}_{2 \mathrm{PP}}$ is expected and typically present in all transparent conducting oxides (TCOs) due to a reduction of oxygen vacancies. Higher densities are obtained at larger $\mathrm{Nb}$ concentrations showing that $\mathrm{Nb}$ is an effective dopant (donor).

However, the minimal resistivity with $5 \mathrm{at} \% \mathrm{Nb}$ is not proportionally lower than with $2.5 \mathrm{at} \%$, as one might expect. Furthermore, the free electron density does not exhibit a cor- 
responding maximum at $55 \% \mathrm{O}_{2 \mathrm{PP}}$ but continues to increase for lower values of $\mathrm{O}_{2 \mathrm{PP}}$. The increase in resistivity with lower $\mathrm{O}_{2 \mathrm{PP}}$ (after the minimum at $\sim 55 \%$ ) is therefore unexpected.

To explain this discrepancy, we consider the mobility as a function of the free electron density; $\mu$ versus $n$, as drawn in Figure 3. The functional dependence is quite usual for TCOs, as reported for example in $[3,23,24]$. Here, samples with an $\mathrm{O}_{2 \mathrm{PP}}$ lower than the resistivity minimum have been neglected, as they show an amorphous microstructure [7]. On the other hand, some samples annealed at higher temperatures and, especially, a few samples with an $\mathrm{Nb}$ concentration of 1 at $\%$ have been included. Specimens with different doping concentrations populate different regions in this plot. Although they can possess the same carrier concentration and similar mobility, they rarely have both in common simultaneously. Therefore, one can already conclude that the mobility of free charge carriers in $\mathrm{TiO}_{2-x}$ is not such a direct function of the carrier concentration as, for example, in $\mathrm{ZnO}: \mathrm{Al}[1,23]$ or $\mathrm{In}_{2} \mathrm{O}_{3}: \mathrm{Sb}$ [24]. This means that, in contrast to common TCOs, in $\mathrm{TiO}_{2-\mathrm{x}}$, additional effects have to be present, which significantly influence the mobility, besides the charge carrier concentration.

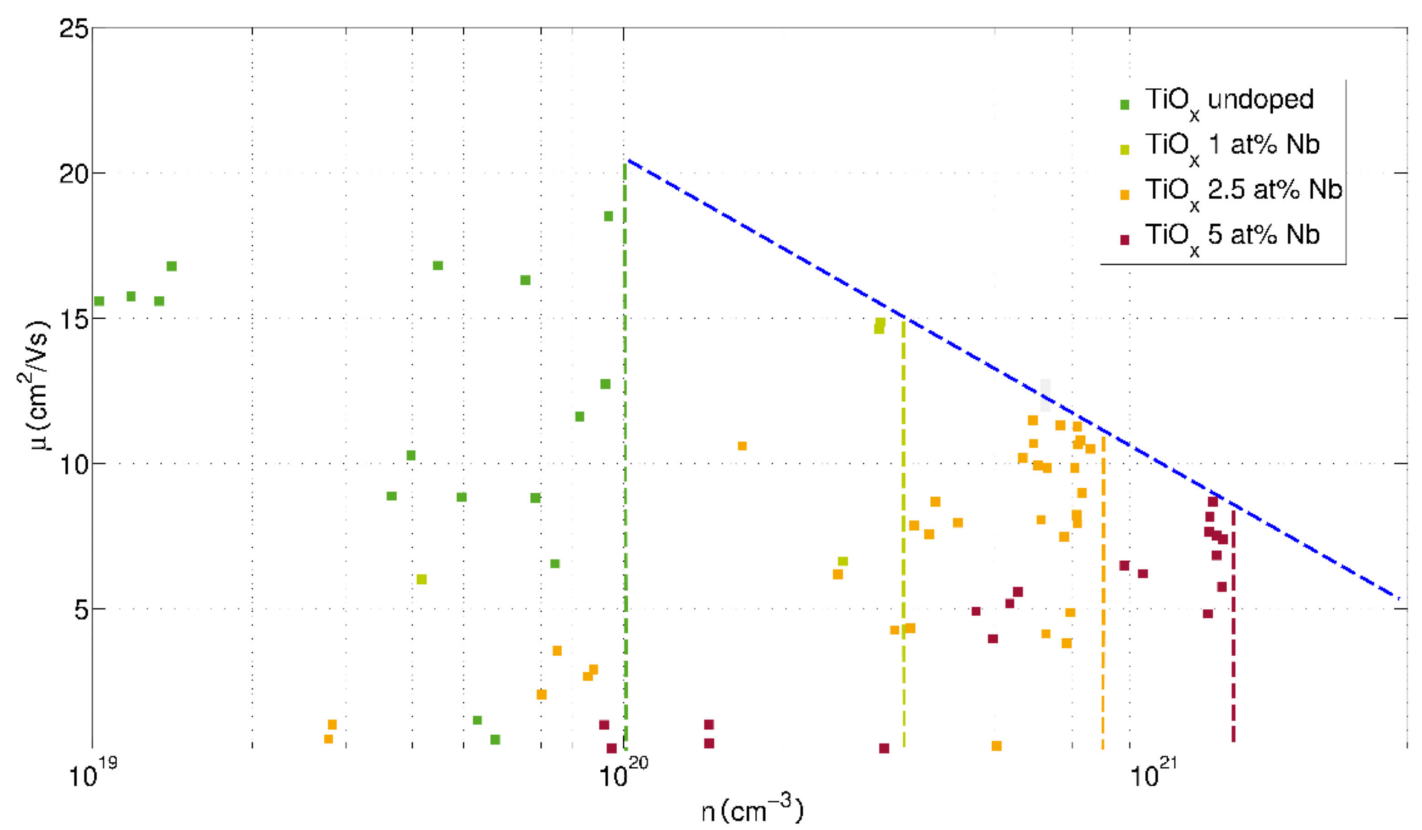

Figure 3. Electron mobility $\mu$ as a function of the free electron density $n$ for different doping concentrations. Here, samples with an $\mathrm{O}_{2 \mathrm{PP}}$ down to the resistivity minimum have been considered, including some films annealed at higher temperatures up to $500{ }^{\circ} \mathrm{C}$ in order to be able to better estimate the respective limits. It can clearly be seen that in this representation, the different compositions populate more or less separated regions. The vertical lines mark the highest electron densities, which seem to be achievable with the corresponding $\mathrm{Nb}$ concentration. The blue line represents the estimated mobility limit of $\mathrm{TiO}_{2-\mathrm{x}}: \mathrm{Nb}$.

Figure 4 displays the mobility as a function of the $\mathrm{O}_{2 \mathrm{PP}}$. If no $\mathrm{Nb}$ is present in the film, the mobility is rising and saturating when increasing the amount of oxygen. This can be understood because a less sub-stoichiometric material contains fewer oxygen vacancies that distort the lattice. A smaller number of such point defects leads to a lattice closer to the ideal $\mathrm{TiO}_{2}$ crystal lattice, and thus, the mobility increases. Below a specific defect density, the vacancies are not a limiting factor anymore so that the mobility saturates.

In the case of $\mathrm{Nb}$-doping, the relationship between mobility and oxygen content during the sputter process changes dramatically. There, not only does the resulting conductivity exhibit a maximum, but the mobility also does. Obviously, the beneficial effect of high oxygen content and fewer oxygen vacancies is not dominating in Nb-doped films, but is superimposed by an additional effect.

In the presence of $\mathrm{Nb}$, why is the mobility and not only the charge carrier concentration also deteriorating with higher oxygen content? The reason for this could be the strong 
tendency of $\mathrm{Nb}$ to oxidize and to form $\mathrm{Nb}_{2} \mathrm{O}_{5}$ precipitates/clusters or to bond with oxygen interstitials. DFT calculations support the idea of $\mathrm{O}_{\mathrm{i}}$ defects near $\mathrm{Nb}$ atoms, which are not present in undoped $\mathrm{TiO}_{2}[9]$.

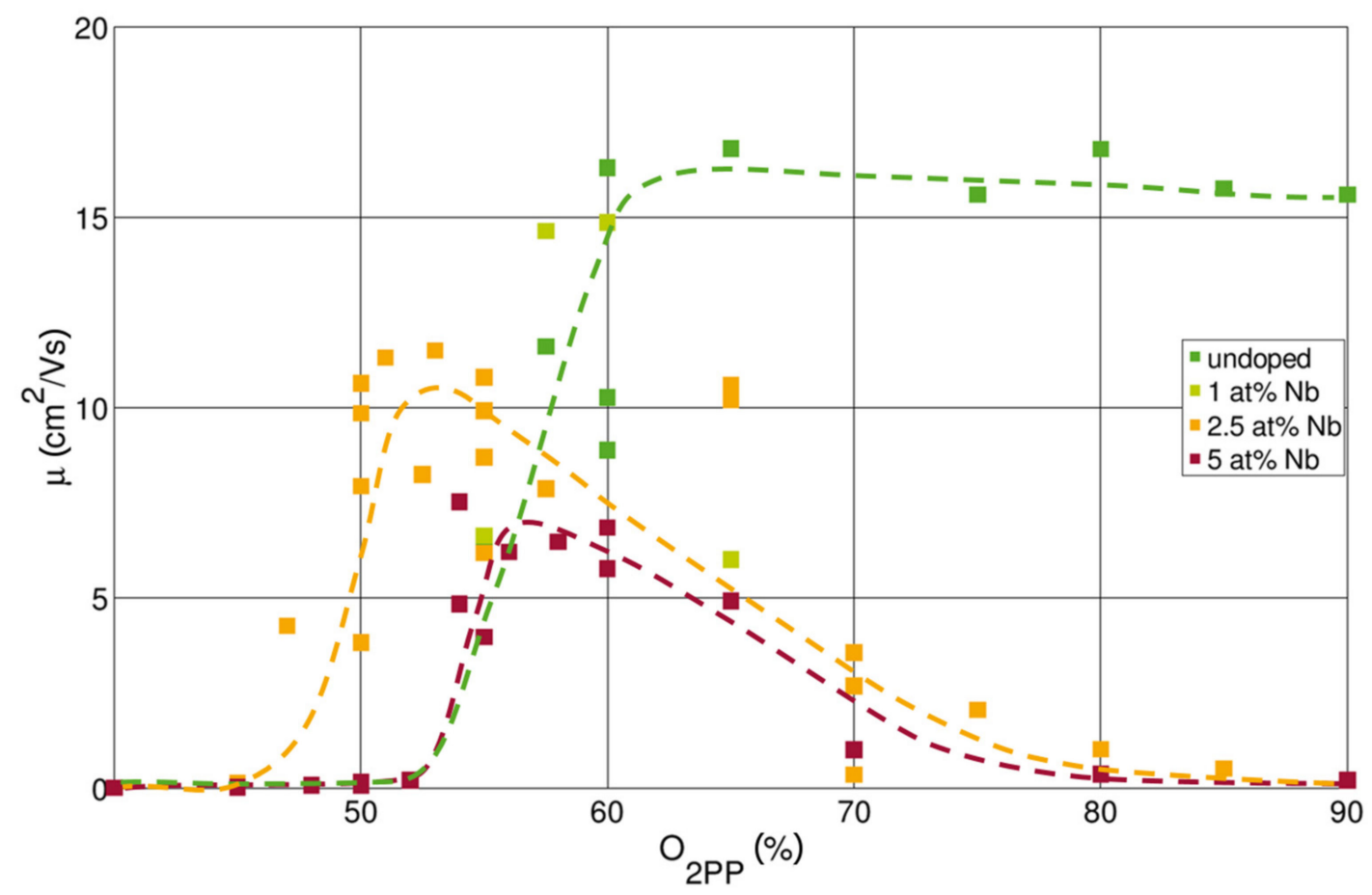

Figure 4. Mobilities $\mu$ as a result of $\mathrm{O}_{2 \mathrm{PP}}$ and the doping concentration with lines as guidance to the eye. The resistivity and charge carrier density $n$ for these samples are shown in Figures 1 and 2. In the undoped case, the mobility arises and finally saturates upon increasing the amount of oxygen. Conversely, if $\mathrm{Nb}$ is present, the mobility drops drastically when adding more oxygen.

This cluster model is supposed to be present in other TCOs as well, for example, in $\mathrm{In}_{2} \mathrm{O}_{3}: \mathrm{Sn}$ at high $\mathrm{O}_{2 \text { PP }}$ [2]. However, the tendency of $\mathrm{Nb}$ to locally form such clusters and the impact of them seem to be much larger. Using the enthalpies of formation of $\mathrm{NbO}_{2}$ $(-795 \mathrm{~kJ} / \mathrm{mol})$ and $\mathrm{Nb}_{2} \mathrm{O}_{5}(-1900 \mathrm{~kJ} / \mathrm{mol})$, it can be concluded that the further oxidation of $\mathrm{NbO}_{2}$ to $\mathrm{Nb}_{2} \mathrm{O}_{5}$ releases an energy of $155 \mathrm{~kJ} / \mathrm{mol}$ with respect to $\mathrm{Nb}$ (in contrast to a difference of $116 \mathrm{~kJ} / \mathrm{mol}$ for $\mathrm{Sn}$ in $\mathrm{Sn}_{2} \mathrm{O}_{3}(-706 \mathrm{~kJ} / \mathrm{mol})$ and $\mathrm{SnO}_{2}(-469 \mathrm{~kJ} / \mathrm{mol})$ showing also their lower reactivity [25]). Thus, if enough thermal energy is provided to enable diffusion of the $\mathrm{Nb}$ atoms and also if sufficient oxygen is available, $\mathrm{Nb}_{2} \mathrm{O}_{5}$ will form. If, on the other hand, an oxygen-poor atmosphere is present, a better comparison is the enthalpy of formation with respect to oxygen. In this case, $\mathrm{Nb}_{2} \mathrm{O}_{5}$ is indeed slightly less (by $\sim 18 \mathrm{~kJ} / \mathrm{mol}$ ) favorable than $\mathrm{NbO}_{2}$, allowing a stable process window for $\mathrm{NbO}_{2}$.

Moreover, this scenario of further oxidizing $\mathrm{NbO}_{2}$ can explain why the carrier densities for doped films can reach values as low as for undoped ones (Figure 4). The harmful effect of the formation of $\mathrm{Nb}_{2} \mathrm{O}_{5}$ on the sample mobility can be understood in terms of $3 \mathrm{D}$ defects. Such insulating (bandgap: $\mathrm{E}_{\mathrm{G}}>4.3 \mathrm{eV}$ [26]) $\mathrm{Nb}_{2} \mathrm{O}_{5}$ precipitates break the lattice symmetry and distort the surrounding matrix, making them strong scatterers. This is in particular true as in $\mathrm{TiO}_{2}$ the conduction band is formed by d-orbitals with a highly directional nature in contrast to the s-orbitals of other TCOs.

Fortunately, $\mathrm{Nb}_{2} \mathrm{O}_{5}$ is energetically also less favorable, with respect to oxygen, than $\mathrm{TiO}_{2}(940 \mathrm{~kJ} / \mathrm{mol})$, as otherwise the dopant would reduce the $\mathrm{TiO}_{2}$ and always form this higher-valence oxide.

This cluster model can explain why different doping concentrations populate different regions in Figure 3, i.e., why, at the same free charge carrier concentration, films with higher $\mathrm{Nb}$ content exhibit much lower mobility. 
The inserted vertical lines in Figure 3 denote approximations for the maximum n, which can be achieved at the different doping levels. Varying approaches like additional $\mathrm{Si}_{3} \mathrm{~N}_{4}$ seed layers, lower sputtering powers, or higher annealing temperatures have been tested, especially in the case of the two higher $\mathrm{Nb}$ contents. However, all samples seem to reach fundamental limits characteristic of polycrystalline $\mathrm{TiO}_{2-\mathrm{x}}: \mathrm{Nb}$ films, not only regarding maximum carrier concentration, but, as indicated by the blue line, also regarding maximum mobility. These limits are summarized in Table 2.

Table 2. List of the approximate limits of $n$ and $\mu$, which arose from Figure 3. The efficiency $v$ of the $\mathrm{Nb}$ doping was calculated, by subtracting $1 \times 10^{20} \mathrm{~cm}^{-3}$, assumed to be the maximum contribution of intrinsic oxygen vacancies. The resulting "excess" electron density was then divided by the $\mathrm{Nb}$ concentration. The 10 at $\%$ values are a prediction, assuming the blue line holds and $v=90 \%$ persist. This would result in a resistivity of about $390 \mu \Omega \mathrm{cm}$. We omitted the efficiency of the $1 \mathrm{at} \%$ as for them the data-base is much smaller.

\begin{tabular}{cccc}
\hline $\mathbf{N b}$ at $\%$ & $n_{\text {limit }}\left(\mathbf{1 0} \mathbf{2 0} / \mathbf{c m}^{3}\right)$ & $\mu_{\text {limit }}\left(\mathbf{c m}^{2} / \mathbf{V s}\right)$ & $\nu_{\mathbf{N b}}(\%)$ \\
\hline 0 & 1 & 20 & - \\
2.5 & 8 & 12 & 96 \\
5 & 14 & 9 & 90 \\
\hline 10 & 27 & 6 & 90 \\
\hline
\end{tabular}

Table 2 also includes the doping efficiency $v$ of $\mathrm{Nb}$. Here, the carrier density limit $\left(1 \times 10^{20} \mathrm{~cm}^{-3}\right)$ of the undoped samples was subtracted from the electron densities of the doped films. We assumed a constant maximum contribution of oxygen vacancies. Otherwise, the efficiency would reach and even overcome a value of $100 \%$ (i.e., one free electron from every $\mathrm{Nb}$ atom). Even so, the calculated efficiencies are around $90 \%$ and above, which is quite outstanding for reactively sputtered TCO films, especially without employing high temperatures or hydrogen treatments. For example, in the case of $\mathrm{Al}$ in $\mathrm{ZnO}: \mathrm{Al}$, maximum efficiencies of typically $50 \%$ are reported [27]. Even films produced very elaborately, exhibiting mobilities and conductivities in the highest possible regime [28], reach only roughly $75 \%$ efficiency, and only by neglecting the contribution of oxygen vacancies as donors.

The linear trend of the relationship between mobility and dopant concentration given by the blue line in Figure 3 can be used to predict the outcome of a further increase of the $\mathrm{Nb}$ content. Such an extrapolation to $10 \mathrm{at} \%$ is given in Table 2, supposing a stable doping efficiency of $90 \%$. Although the maximum mobility is supposed to decrease further, the higher charge carrier density could reduce the resistivity to $390 \mu \Omega \mathrm{cm}$. Reaching such low values for films on glass obtained with a reactive sputter process at room temperature and moderate annealing would be a considerable advancement.

The observation that the maximum achievable mobility decreases with increasing $\mathrm{Nb}$ concentration, as indicated by the blue line, can be understood quite intuitively. Even if the maximum is achieved when nearly no $\mathrm{Nb}_{2} \mathrm{O}_{5}$ clusters are present, the $\mathrm{Nb}$ atoms with their larger ionic radius distort the lattice and thus lower the mobility. Additionally, after they have donated effectively an additional electron into the conduction band, they are more charged, increasing the scattering probability via a larger cross-section.

Such a dominant dependency of the mobility on the dopant concentration indicates that the mobility in $\mathrm{TiO}_{2}$ is very prone to any kind of lattice distortion. In a previous study about undoped $\mathrm{TiO}_{2}$ [7], it was shown that sharply below a specific $\mathrm{O}_{2 \mathrm{PP}}$ value, the films do not crystallize during annealing even when employing higher temperatures up to $500{ }^{\circ} \mathrm{C}$. The same behavior can also be seen for $\mathrm{Nb}$-doped films, for example, in Figure 5 (and Figure A2), where some XRD patterns are displayed. Below an $\mathrm{O}_{2 \mathrm{PP}}$ of about 50\%, the films stay amorphous; this correlates with the nearly zero mobility shown in Figure 4. Additionally, the films sputtered at higher $\mathrm{O}_{2 \mathrm{PP}}$ values show slightly reduced intensity despite the same thickness, which also correlates with the decreasing electron mobility. 


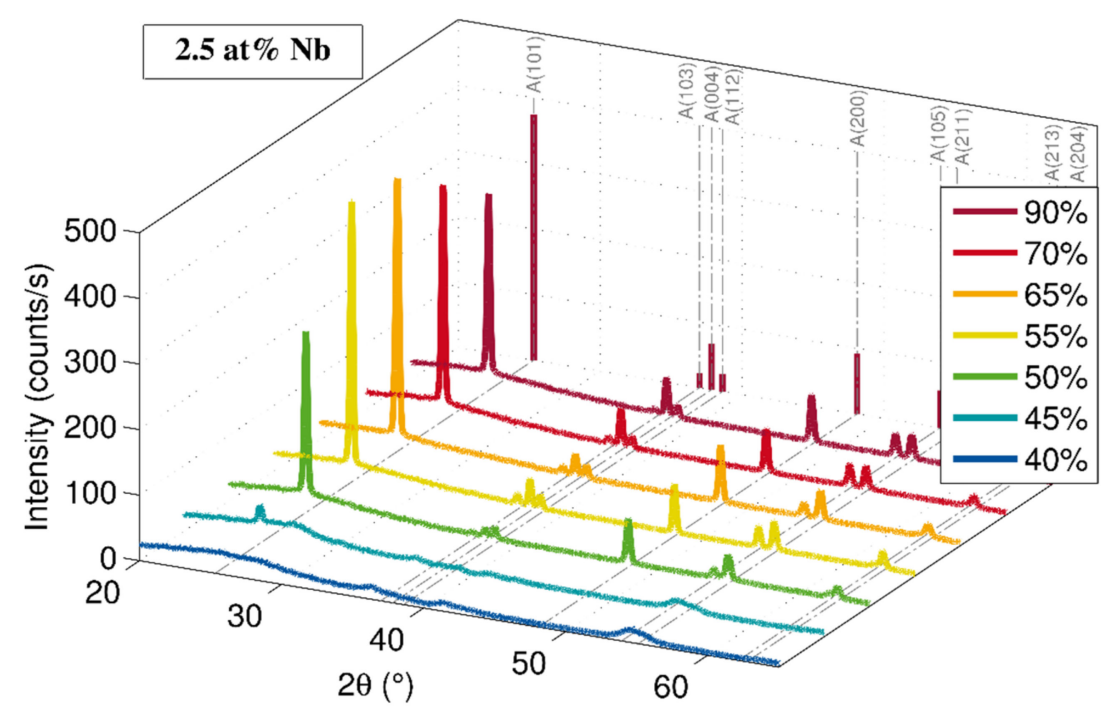

Figure 5. XRD pattern of $\mathrm{TiO}_{2-\mathrm{x}}$ films doped with $2.5 \mathrm{at} \% \mathrm{Nb}$ sputtered at different $\mathrm{O}_{2 \mathrm{PP}}$. All films were about $250 \mathrm{~nm}$ thick, capped, annealed at $300{ }^{\circ} \mathrm{C}$ for $2 \mathrm{~h}$ and measured in grazing incidence geometry. All evolving reflexes belong to the anatase phase (powder pattern is illustrated by the dashed lines and at the back wall of the $3 \mathrm{D}$ plot). Capped films sputtered with $\mathrm{O}_{2 \mathrm{PP}}$ values below $55 \%$ stay amorphous even when annealed at higher temperatures of up to $500{ }^{\circ} \mathrm{C}$.

As stated previously, the difference of several orders of magnitude in electron mobility between the amorphous and crystalline states can be explained by the highly directional nature of $d$-orbitals that form the conduction band in $\mathrm{TiO}_{2}$. This is in contrast to standard TCOs, where spherical s-orbitals govern the electrical transport, thus not suffering much by an amorphous structure. With this, the high vulnerability of the mobility to the $\mathrm{Nb}$ doping and $\mathrm{Nb}_{2} \mathrm{O}_{5}$ cluster formation, causing distortions of the lattice, can be understood. However, as can be seen by the absence of any reflexes in the XRD not caused by $\mathrm{TiO}_{2}$ (anatase), there are no precipitations of pure $\mathrm{Ti} / \mathrm{Nb}, \mathrm{Nb}_{2} \mathrm{O}_{5}, \mathrm{TiO}_{2}$ (rutile) etc., large enough to be detectable.

To summarize, the minimum of the resistivity as a function of the oxygen partial pressure in Figure 1 can be explained by a low charge carrier density and mobility caused by $\mathrm{Nb}_{2} \mathrm{O}_{5}$ cluster formation towards higher $\mathrm{O}_{2 \mathrm{PP}}$ values and low mobility due to the suppressed crystallization towards lower $\mathrm{O}_{2 \mathrm{PP}}$ values.

Finally, the transmittance in the visible range has been investigated. The data presented in Figure 6 demonstrate that a high transmittance above $80 \%$ can be achieved. This is the case for wavelengths larger than the fundamental absorption $(\sim 350 \mathrm{~nm})$ originating from the bandgap. $\mathrm{TiO}_{2-x}$ films exhibit a high reflectance of about $20 \%$ due to their very high refractive index of 2.5, which is characteristic of the anatase phase [29]. Details about the optical properties of $\mathrm{TiO}_{2-\mathrm{x}}$ and the dependency on the $\mathrm{O}_{2 \mathrm{PP}}$ can be found elsewhere [7]. As can be seen in Figure 6, the additional $\mathrm{Nb}$ doping had no detrimental effects on the transparency. This indicates that no additional absorption caused by levels introduced in the band gap or metal nanoparticles are present. These findings emphasize an advantage of the $\mathrm{TiO}_{2}: \mathrm{Nb}$ system compared to other TCOs: higher dopability without a reduction in transparency. In our films, charge carrier concentrations of up to $1.4 \times 10^{21} \mathrm{~cm}^{-3} \mathrm{do}$ not show any reduction in transparency compared to films with more than an order of magnitude smaller carrier density.

The higher dielectric constant $\varepsilon_{\infty}$ and effective mass of the electrons $m^{*}$ in $\mathrm{TiO}_{2}$ (anatase) reduce the plasma frequency [30]:

$$
\omega_{P} \propto \sqrt{\frac{n}{m^{*} \epsilon_{\infty}}},
$$




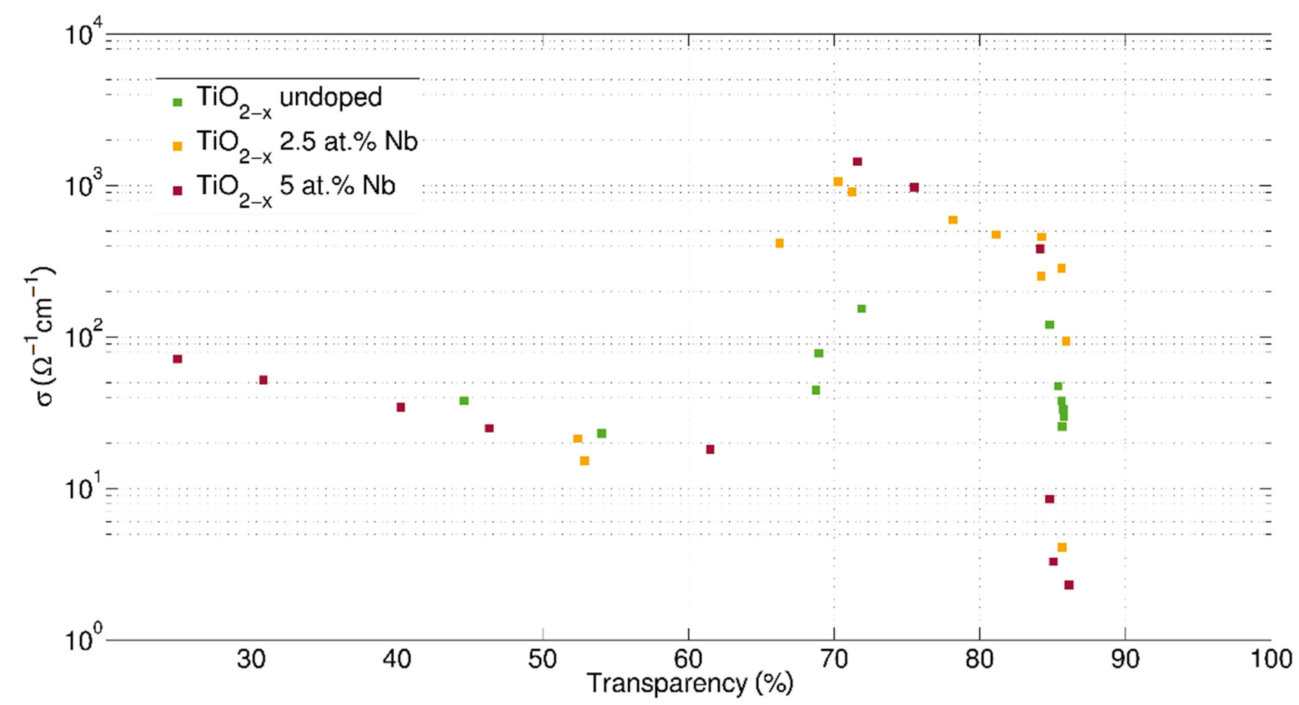

Figure 6. Conductivity $\sigma$ at room temperature as a function of the transparency for a selection of $\mathrm{TiO}_{2-\mathrm{x}}: \mathrm{Nb}$ films. The observed maximum transparency of $85 \%$ is limited by reflectivity and could already be increased to more than $90 \%$ by some first tests with non-optimized $\mathrm{Si}_{3} \mathrm{~N}_{4}$ seed layers. In contrast to common TCOs, a clear optimal range of conductivity and transparency at $70-80 \%$ can be observed.

This allows the introduction of a higher carrier density than in standard TCOs before absorption in the red/infrared spectrum becomes important. Therefore, in standard TCOs, $n$ is less than $1 \times 10^{21} \mathrm{~cm}^{-3}[3,4,31]$. Moreover, the solubility of $\mathrm{Nb}$ in $\mathrm{TiO}_{2}$ is also quite high, and concentrations of up to 10 at $\%$ or even 20 at $\%$ are possible without formation of precipitates [5,32], whereas, e.g., less than 2.5 at $\% \mathrm{Al}$ in $\mathrm{ZnO}$ can be introduced [33].

On the other spectral side, at the low wavelength regime, we obtained a band gap of $3.3 \mathrm{eV}$ for the undoped $\mathrm{TiO}_{2-\mathrm{x}}$ and about $3.5 \mathrm{eV} \pm 0.1 \mathrm{eV}$ for the $\mathrm{Nb}$-doped films, $2.5 \mathrm{at} \%$ and 5 at $\%$ as well, which are in the range of the measurement uncertainty. The high charge carrier density dominates the behavior for the $\mathrm{Nb}$ doped films due to the Burstein-Moss band-filling effect.

Usually, in TCOs, transparency and conductivity are inversely linked, and a tradeoff must be made. This is not so much the case for $\mathrm{TiO}_{2-\mathrm{x}}: \mathrm{Nb}$, as optimal transparency and conductivity coincide within the same process window. A common figure of merit proposed by Gordon is the ratio of conductivity $\sigma$ and absorption coefficient $\alpha$ [4]:

$$
\frac{\sigma}{\alpha}=-\frac{1}{R_{\text {sheet }} \times \ln (T+R)},
$$

where $R_{\text {sheet }}$ is the sheet resistivity, and $T$ and $R$ the total transmittance and total reflectance, respectively. He gave some values for TCO materials with different dopants like $\mathrm{ZnO}: \mathrm{F}$, $\mathrm{In}_{2} \mathrm{O}_{3}: \mathrm{Sn}$, or $\mathrm{SnO}_{2}: \mathrm{Sb}$, which varied between 0.2 and $7 \Omega^{-1}$. Applying this formula, the best films produced in this study, including a $\mathrm{Si}_{3} \mathrm{~N}_{4}$ seed layer and a capping layer, achieved values between 1 and even $6 \Omega^{-1}$. As $\mathrm{TiO}_{2}$ is still a relatively uncommon $\mathrm{TCO}$ and was discovered several decades later than the others, we think there is still considerable room for improvement of its performance, e.g., using higher doping concentrations as indicated in Table 2.

\section{Conclusions}

Highly conductive $(\rho=630 \mu \Omega \mathrm{cm}$ with 5 at $\% \mathrm{Nb})$ and transparent $(\mathrm{T}=70-80 \%$ and reflectivity $20 \%$ ) $\mathrm{Nb}$-doped films on glass with the industry-relevant method of reactive magnetron sputtering have been produced, employing a fast feedback control loop of the oxygen partial pressure $\mathrm{O}_{2 \mathrm{PP}}$ and a simple low-temperature annealing at $300{ }^{\circ} \mathrm{C}$. The influence of $\mathrm{O}_{2 \mathrm{PP}}$ and $\mathrm{Nb}$ content on electric film properties has been investigated, and 
a detailed model was presented explaining the observed differences, especially between doped and undoped conductive $\mathrm{TiO}_{2-x}$ samples. The lower mobility of doped as compared to undoped $\mathrm{TiO}_{2}$ with the same electron density may be explained by the formation of $\mathrm{Nb}_{2} \mathrm{O}_{5}$ clusters acting as scattering centers. A very high doping efficiency of $\mathrm{Nb}$ of above $90 \%$ was measured, and intrinsic limits of the mobility could be observed, allowing a prediction of the lowest achievable resistivities for other doping concentrations. An optimal (in terms of transparency and conductivity) but also very narrow process window of only $1 / 10$ of the full gap between oxidic and metallic sputtering was found.

Extrapolating a linear trend, a minimum resistivity of about $400 \mu \Omega \mathrm{cm}$ is predicted for $10 \mathrm{at} \% \mathrm{Nb}$. These findings indicate that the application potential of $\mathrm{Nb}$-doped $\mathrm{TiO}_{2}$ may still be increased significantly.

Author Contributions: Conceptualization, D.D.-G.; methodology, D.D.-G.; validation, all authors; formal analysis, D.D.-G.; investigation, D.D.-G.; resources, M.W.; writing-original draft preparation, D.D.-G.; writing-review and editing, D.M.; visualization, D.D.-G.; supervision, M.W.; project administration, M.W.; funding acquisition, M.W. All authors have read and agreed to the published version of the manuscript.

Funding: This research received no external funding.

Institutional Review Board Statement: Not applicable.

Informed Consent Statement: Not applicable.

Data Availability Statement: Data are provided in the figures of the article.

Acknowledgments: We want to thank Mona Förster, Stephan Hermes, and Simon von Oehsen for their experimental support.

Conflicts of Interest: The authors declare no conflict of interest. The funders had no role in the design of the study; in the collection, analyses, or interpretation of data; in the writing of the manuscript, or in the decision to publish the results.

\section{Appendix A}

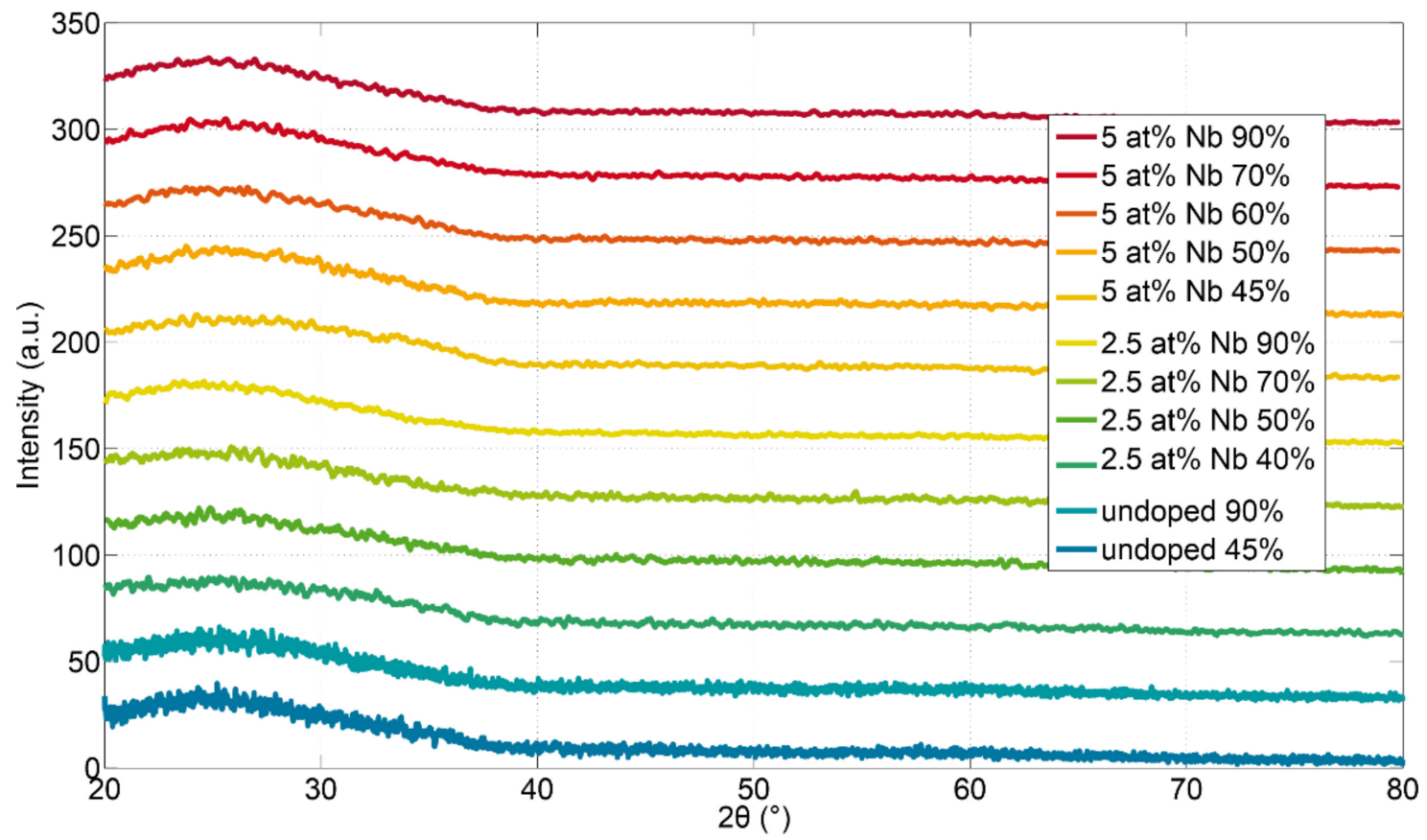

Figure A1. XRD in grazing incident geometry of as-deposited films with and without $\mathrm{Nb}$ doping confirming the amorphous structure before annealing. 


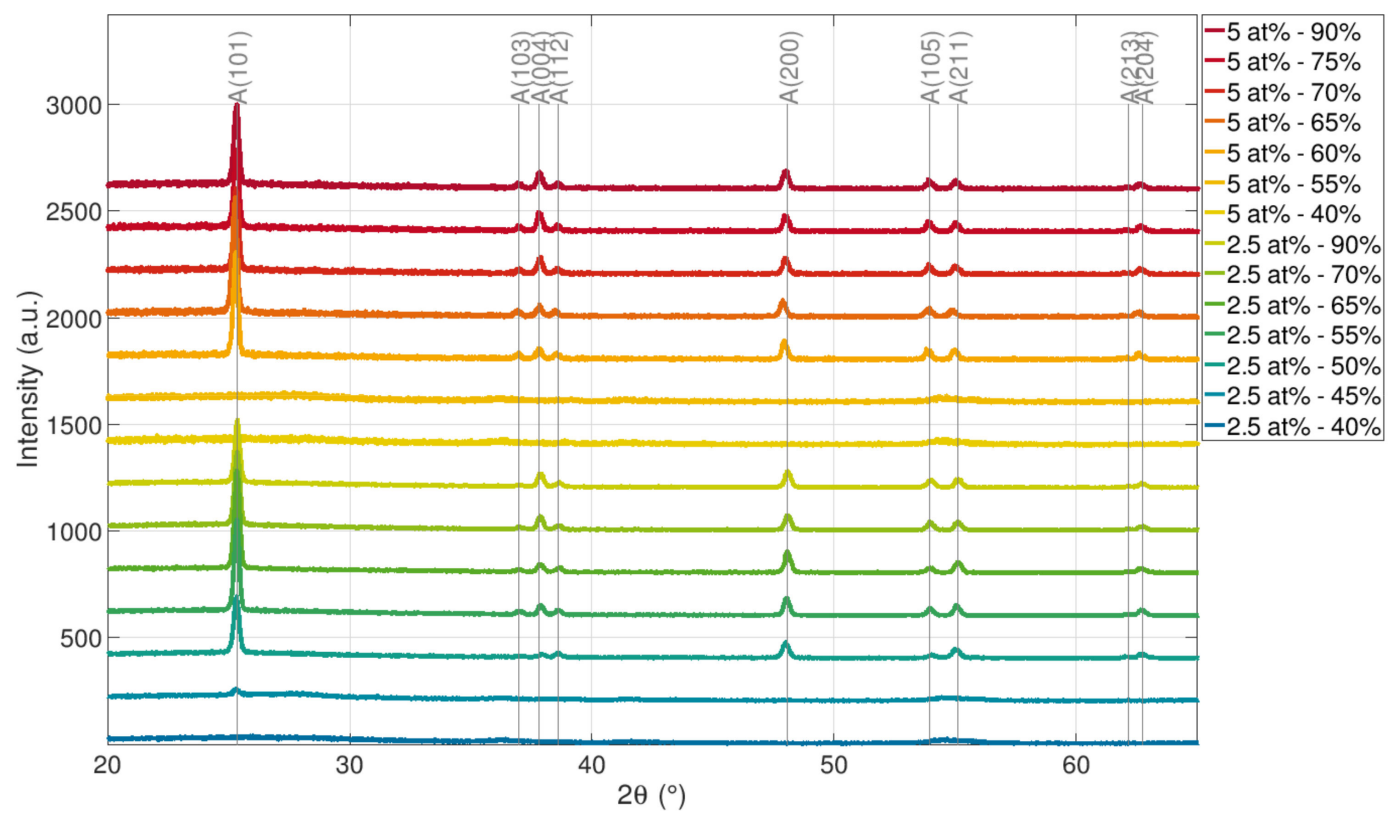

Figure A2. XRD in grazing incident geometry of $\mathrm{Nb}$-doped films sputtered at different $\mathrm{O}_{2 \mathrm{PP}}$ levels, after annealing at $300{ }^{\circ} \mathrm{C}$ for $2 \mathrm{~h}$. Only anatase reflexes are found and films with insufficient oxygen content remained amorphous, which was previously reported for undoped $\mathrm{TiO}_{2-x}[7]$.

\section{References}

1. Ginley, D.S.; Perkins, J.D. Transparent Conductors. In Handbook of Transparent Conductors, 1st ed.; Ginley, D.S., Hosono, H., Paine, D.C., Eds.; Springer Science+Business Media: New York, NY, USA, 2010; pp. 1-25. [CrossRef]

2. Bright, C. Review of Transparent Conductive Oxides (TCO). Mattox DM Mattox VH 2007, 50, $38-45$.

3. Edwards, P.P.; Porch, A.; Jones, M.O.; Morgan, D.V.; Perks, R.M. Basic materials physics of transparent conducting oxides. Dalton Trans. 2004, 19, 2995-3002. [CrossRef]

4. Gordon, R.G. Criteria for Choosing Transparent Conductors. MRS Bull. 2000, 25, 52-57. [CrossRef]

5. Furubayashi, Y.; Hitosugi, T.; Yamamoto, Y.; Inaba, K.; Kinoda, G.; Hirose, Y.; Shimada, T.; Hasegawa, T. A transparent metal: Nb-doped anatase $\mathrm{TiO}_{2}$. Appl. Phys. Lett. 2005, 86, 252101. [CrossRef]

6. Hitosugi, T.; Kamisaka, H.; Yamashita, K.; Nogawa, H.; Furubayashi, Y.; Nakao, S.; Yamada, N.; Chikamatsu, A.; Kumigashira, H.; Oshima, M.; et al. Electronic Band Structure of Transparent Conductor: Nb-Doped Anatase $\mathrm{TiO}_{2}$. Appl. Phys. Express 2008, 1, 111203. [CrossRef]

7. Dorow-Gerspach, D.; Wuttig, M. Metal-like conductivity in undoped $\mathrm{TiO}_{2-\mathrm{x}}$ : Understanding an unconventional transparent conducting oxide. Thin Solid Film. 2019, 669, 1-7. [CrossRef]

8. Hirose, Y.; Yamada, N.; Nakao, S.; Hitosugi, T.; Shimada, T.; Hasegawa, T. Large electron mass anisotropy in a delectron-based transparent conducting oxide: $\mathrm{Nb}$-doped anatase $\mathrm{TiO}_{2}$ epitaxial films. Phys. Rev. B 2009, 79, 165108. [CrossRef]

9. Kamisaka, H.; Hitosugi, T.; Suenaga, T.; Hasegawa, T.; Yamashita, K. Density functional theory based first-principle calculation of $\mathrm{Nb}$-doped anatase $\mathrm{TiO}_{2}$ and its interactions with oxygen vacancies and interstitial oxygen. J. Chem. Phys. 2009, 131, 034702 [CrossRef] [PubMed]

10. Sato, Y.; Akizuki, H.; Kamiyama, T.; Shigesato, Y. Transparent conductive $\mathrm{Nb}$-doped $\mathrm{TiO}_{2}$ films deposited by direct-current magnetron sputtering using a $\mathrm{TiO}_{2-x}$ target. Thin Solid Film. 2008, 516, 5758-5762. [CrossRef]

11. Sato, Y.; Sanno, Y.; Tasaki, C.; Oka, N.; Kamiyama, T.; Shigesato, Y. Electrical and optical properties of $\mathrm{Nb}^{-\mathrm{doped}} \mathrm{TiO}{ }_{2}$ films deposited by dc magnetron sputtering using slightly reduced $\mathrm{Nb}$-doped $\mathrm{TiO}_{2-x}$ ceramic targets. J. Vac. Sci. Technol. A 2010, 28, 851-855. [CrossRef]

12. Hoang, N.L.H.; Yamada, N.; Hitosugi, T.; Kasai, J.; Nakao, S.; Shimada, T.; Hasegawa, T. Low-temperature Fabrication of Transparent Conducting Anatase $\mathrm{Nb}$-doped $\mathrm{TiO}_{2}$ Films by Sputtering. Appl. Phys. Express 2008, 1, 115001. [CrossRef]

13. Ellmer, K. Magnetron sputtering of transparent conductive zinc oxide: Relation between the sputtering parameters and the electronic properties. J. Phys. D Appl. Phys. 2000, 33, R17. [CrossRef]

14. Tang, H.; Prasad, K.; Sanjines, R.; Schmid, P.E.; Levy, F. Electrical and optical properties of $\mathrm{TiO}_{2}$ anatase thin films. J. Appl. Phys. 1994, 75, 2042-2047. [CrossRef]

15. Berg, S.; Nyberg, T. Fundamental understanding and modeling of reactive sputtering processes. Thin Solid Film. 2005, 476, 215-230. [CrossRef]

16. Dorow-Gerspach, D. $\mathrm{TiO}_{2}-\mathrm{A}$ Study of Electrical, Dielectric and Structural Features as a Route towards Understanding a Novel Transparent Conductive Oxide. Ph.D. Thesis, RWTH-Aachen, Aachen, Germany, 2017. [CrossRef] 
17. Singhal, S.C. Thermodynamics and kinetics of oxidation of hot-pressed silicon nitride. J. Mater. Sci. 1976, 11, 500-509. [CrossRef]

18. Dannenberg, R.; Greene, P. Reactive sputter deposition of titanium dioxide. Thin Solid Film. 2000, 360, 122-127. [CrossRef]

19. Swanepoel, R. Determination of the thickness and optical constants of amorphous silicon. J. Phys. E: Sci. Instruments 1983, 16, 1214-1222. [CrossRef]

20. Lany, S.; Zunger, A. Dopability, Intrinsic Conductivity, and Nonstoichiometry of Transparent Conducting Oxides. Phys. Rev. Lett. 2007, 98, 045501. [CrossRef]

21. Oka, N.; Sanno, Y.; Jia, J.; Nakamura, S.I.; Shigesato, Y. Transparent conductive Nb-doped $\mathrm{TiO}_{2}$ films deposited by reactive dc sputtering using Ti-Nb alloy target, precisely controlled in the transition region using impedance feedback system. Appl. Surf. Sci. 2014, 301, 551-556. [CrossRef]

22. Mukherjee, S.K.; Becker, H.W.; Bedini, A.C.; Nebatti, A.; Notthoff, C.; Rogalla, D.; Schipporeit, S.; Soleimani-Esfahani, A.; Mergel, D. Structural and electrical properties of $\mathrm{Nb}$-doped $\mathrm{TiO}_{2}$ films sputtered with plasma emission control. Thin Solid Film. 2014, 568, 94-101. [CrossRef]

23. Ellmer, K. Resistivity of polycrystalline zinc oxide films: Current status and physical limit. J. Phys. D Appl. Phys 2001, 34, 3097. [CrossRef]

24. Preissler, N.; Bierwagen, O.; Ramu, A.T.; Speck, J.S. Electrical transport, electrothermal transport, and effective electron mass in single-crystalline $\mathrm{In}_{2} \mathrm{O}_{3}$ films. Phys. Rev. B 2013, 88, 085305. [CrossRef]

25. Sarker, P.; Huda, M.N. Understanding the thermodynamic pathways of SnO-to-SnO phase transition. Comput. Mater. Sci. 2015, 111, 359-365. [CrossRef]

26. Agarwal, G.; Reddy, G.B. Study of surface morphology and optical properties of $\mathrm{Nb}_{2} \mathrm{O}_{5}$ thin films with annealing. J. Mater. Sci. Mater. Electron. 2005, 16, 21-24. [CrossRef]

27. Szyszka, B. Transparente und leitfähige Oxidschichten. Vak. Forsch. Und Prax. 2001, 13, 38-45. [CrossRef]

28. Hüpkes, J.; Owen, J.I.; Wimmer, M.; Ruske, F.; Greiner, D.; Klenk, R.; Zastrow, U.; Hotovy, J. Damp heat stable doped zinc oxide films. Thin Solid Film. 2014, 555, 48-52. [CrossRef]

29. Hanaor, D.H.; Sorrell, C. Review of the anatase to rutile phase transformation. J. Mater. Sci. 2011, 46, 855-874. [CrossRef]

30. Bid, A.; Bora, A.; Raychaudhuri, A.K. Temperature dependence of the resistance of metallic nanowires of diameter 150nm: Applicability of Bloch-Grüneisen theorem. Phys. Rev. B 2006, 74, 035426. [CrossRef]

31. Castañeda, L. Present Status of the Development and Application of Transparent Conductors Oxide Thin Solid Films. Mater. Sci. Appl. 2011, 09, 1233-1242. [CrossRef]

32. Ruiz, A.M.; Dezanneau, G.; Arbiol, J.; Cornet, A.; Morante, J.R. Insights into the Structural and Chemical Modifications of Nb Additive on $\mathrm{TiO}_{2}$ Nanoparticles. Chem. Mater. 2004, 16, 862-871. [CrossRef]

33. Yoon, M.H.; Lee, S.H.; Park, H.L.; Kim, H.K.; Jang, M.S. Solid solubility limits of Ga and Al in ZnO. J. Mater. Sci. Lett. 2002, 21, 1703-1704. [CrossRef] 